\title{
A Gestão do Design e os Espaços Coworking: Estudo de Caso Exploratório
}

The Design Management and the Coworking Spaces: Exploratory Case Study

PRADO, Gheysa Caroline; Doutoranda; UFPR | UTP

gheysa.p@gmail.com

PELEGRINI, Alexandre Vieira, Doutor, UTFPR

avpelegrini@googlemail.com

KISTMANN, Virgínia Souza de Carvalho Borges, Doutora, UFPR

vkistimann@ufpr.br

\section{Resumo}

O presente artigo investiga como uma empresa de espaço coworking da cidade de Curitiba aplica elementos do nível estratégico da gestão do design no nível tático da empresa. Utilizando-se de um estudo de caso exploratório, foi realizada uma revisão de literatura, seguida de visita para observação e entrevista para coleta de dados para análise do espaço estudado. Os resultados apontam para um uso de técnicas de gestão do design em ambos os níveis pretendidos, estratégico e tático. Tal aplicação foi feita de modo empírico, mas manteve o objetivo de diferenciação e inovação da gestão do design frente às empresas concorrentes.

Palavras Chave: economia criativa; gestão do design; espaço coworking

\section{Abstract}

The aim of this paper is to identify the application of elements from the strategic level of design management at the tactic level of a coworking space company in Curitiba. An exploratory case study was conducted using literature review, observation and interview as data collection tools to analyze the space. The results point out elements of both levels o design management within the company, strategic and tactic. The use of these are empirical, thou the goals are as aimed by the design management, differentiation and innovation ahead of the market.

Keywords: creative economy; design management; coworking space.

\section{Introdução}

Em decorrência das crises econômica e financeira de 2007/2008 seguida de uma recessão global houve rápido aumento de espaços coworking em diversas cidades do mundo sendo este, de acordo com Merkel (2015) um fenômeno essencialmente urbano. Esse aumento, da perspectiva urbanística, segundo a mesma autora, pode ser visto também como 
reflexo dos constantes processos de reurbanizações das cidades que levaram à gentrificação ${ }^{1}$ de diversas áreas. Ao longo dos anos, esses espaços cresceram como lugares para empreendedores e profissionais autônomos ligados à economia criativa e às novas formas de trabalho, atraindo a atenção e gerando interesse da comunidade acadêmica para o desenvolvimento de novas pesquisas sobre o assunto (KORUNKA e GERDENITSCH, 2014).

A interesse da comunidade acadêmica cresce à medida em que crescem o número de espaços coworking ao redor do mundo. De acordo com Foertsch (2010), antes de 2010, poucos estudos acadêmicos haviam sido conduzidos sobre os espaços coworking. De acordo com De Pellegrin e Foertsch (2011), naquele mesmo ano, havia 703 espaços coworking em âmbito global. Entretanto, nos últimos 5 anos, esse número cresceu mais de 10 vezes, chegando a mais de 7800 espaços em 2015 (FOERTSCH, 2015).

Devido ao exponencial crescimento no número de espaços coworking nos últimos anos, torna-se importante estudar acerca dos processos de gestão adotados por essas empresas. Suas características estruturais mais planas e flexíveis e suas relações com as novas formas de trabalho demandam planos gerenciais que respondam positivamente e atendam à essas perticularidades. A gestão do design, conforme descrita por Klöpsh et al. (2011), possui aspectos colaborativos e participativos, que poderiam ser adequadamente alinhados às demandas dos gestores de espaços coworking.

Este estudo exploratório conduziu, portanto, um estudo de caso para analisar aspectos da gestão do design presentes na primeira empresa de espaço coworking inaugurada em Curitiba-PR em 2010, tendo como pergunta de pesquisa: "Como os conceitos de gestão do design definidos pela empresa de espaço coworking no nível estratégico são aplicados em no nível tático?". O objetivo foi identificar as definições feitas pela empresa de espaço coworking no nível estratégico e, posteriormente, comparar e verificar como essas definições se refletem nas ações tomadas pela empresa no nível tático.

O trabalho está estruturado da seguinte forma: o coworking e suas características físicas; a gestão do design no cenário da economia criativa; o estudo de caso; discussão e considerações finais.

\section{As Novas Formas de Trabalho e o Papel das Empresas de Espaços Coworking}

$\mathrm{O}$ surgimento e crescimento tanto da economia do conhecimento como da economia criativa estão diretamente ligados à globalização, à popularização de novos meios de comunicação e das mídias sociais (HOSPERS, 2003). Tais fatores levaram ao desenvolvimento de novas formas de trabalho, mais flexíveis e com foco na humanização democratização (KOVÁCS, 2006). Trabalho flexível pode ser definido como o tipo de atividade projetada de maneira a permitir que os empregados definam, de forma autônoma, seu cronograma e local de trabalho (HILL et al., 2008). De acordo com Johns e Gratton (2013) o trabalho flexível ou trabalho virtual pode ser dividido em três momentos: primeiro, o profissional autônomo virtual; segundo, os colegas de empresa virtuais; e terceiro, os coworkers virtuais (Figura 1). Cada momento se desenvolveu a partir de uma dificuldade enfrentada pelo precedente sem, no entanto, suprimir o anterior, adicionando novas possibilidades de flexibilização.

\footnotetext{
${ }^{1}$ Processo de valorização imobiliária de uma zona urbana, geralmente acompanhada do deslocamento dos residentes com menor poder econômico para outro local e da entrada de residentes com maior poder econômico.
} 


\begin{tabular}{|c|c|c|c|c|}
\hline $\begin{array}{r}\text { Figura } 1 \\
\text { Autônomo }\end{array}$ & $\mathrm{M}$ & $\begin{array}{l}\text { mentos do Trabs } \\
\text { mpregados } \\
\text { virtuais }\end{array}$ & & Coworkers \\
\hline $\begin{array}{l}\text { Talentos } \\
\text { marginalizados } \\
\text { Resultados por } \\
\text { e-mail } \\
\text { Flexibilidade } \\
\text { para empresas e } \\
\text { empregados }\end{array}$ & $\begin{array}{l}\frac{1}{n} \\
\frac{0}{u} \\
\frac{i}{4} \\
\frac{2}{0} \\
0 \\
\frac{0}{0} \\
\frac{\pi}{0} \\
\frac{\pi}{0} \\
\frac{2}{0}\end{array}$ & $\begin{array}{l}\text { Equipe global } \\
\text { Trabalho } \\
\text { remoto } \\
\text { Possibilidade } \\
\text { de progresso na } \\
\text { carreita }\end{array}$ & 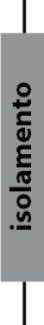 & $\begin{array}{l}\text { Espaço } \\
\text { compartilhado } \\
\text { Redução do } \\
\text { isolamento } \\
\text { Motivador de } \\
\text { colaboração }\end{array}$ \\
\hline
\end{tabular}

Fonte: Adaptado de Johns e Gratton (2013)

Com a popularização das novas formas de trabalho cresce a necessidade de espaços adequados para realização das tarefas. Escritórios residenciais, cafés, restaurantes e bibliotecas eram, no início, as únicas opções destes trabalhadores, no entanto, foram progressivamente sendo percebidas como inapropriadas por diversas razões. De problemas de concentração e falta de privacidade nos espaços públicos à solidão e distrações com as atividades domésticas em casa. Profissionais autônomos, trabalhadores flexíveis e empreendedores de diferentes áreas precisavam de um local que lhes oferecesse mais do que um assento e internet. Precisavam de um lugar para interação, colaboração e cooperação. Foi dentro desse contexto e baseado nesses valores que o conceito de espaços coworking se desenvolveram (FOERTSCH, 2010; BILANDZIC AND FOTH, 2013).

O conceito de coworking, na forma em que é tratado nesta pesquisa, surgiu em 2005, primeiro como uma rede em Londres e, então, como um espaço físico em São Francisco nos Estados Unidos da América cujo significado vai além de um espaço de trabalho compartilhado (LEFORESTIER 2009). Diferencia-se de espaços convencionais de trabalho, cafés e escritórios residenciais por seus valores que se baseiam nos conceitos de abertura, colaboração, acessibilidade e comunidade. A abertura tem o foco na transparência de ideias, que beneficiam a todos e deixam espaços abertos a discussões. A colaboração parte do princípio que as diferentes pessoas envolvidas possuem diferentes conhecimentos a serem compartilhados. A acessibilidade trata do espaço físico, mas também do ponto de vista financeiro. E, a comunidade, enfatiza a possibilidade de conexões e suporte mútuo entre os usuários (GANDINI, 2015 e MORISET, 2014).

Em menos de uma década, o número de empresas de espaços coworking no mercado cresceu de forma significativa, de 703 lugares conhecidos em 2010 para mais de 7800 em 2015, sem sinais de saturação. Atualmente, cerca de meio milhão de pessoas trabalham em espaços coworking, e a estimativa é de que esse número continue crescendo, podendo atingir, de acordo com alguns estudos, mais de um bilhão de pessoas adeptas do trabalho flexível (DE PELLEGRIN AND FOERTSCH, 2011; JOHNS AND GRATTON, 2013; FOERTSCH, 2015).

Dados brasileiros, apesar de mais recentes, mostram que em 2013 havia pouco mais de 100 empresas de espaços coworking em território nacional, número que subiu para 238 empresas em 2015. De acordo com Ekonomio (2015), 105 das empresas brasileiras entrevistadas declararam não possuir uma área profissional específica como foco de público alvo. Entretanto, o estudo mostrou uma concentração comum de pessoas e empresas das 
seguintes áreas profissionais nos espaços coworking do Brasil: empreendedores sociais, design, moda, educação, startups, advogados, informática e artes. Do número total de empresas de espaços coworking existentes no Brasil em março de 2015, 69 estavam localizadas em São Paulo. Em Curitiba, a cidade onde o estudo foi conduzido, possuía na mesma data 13 empresas, sendo a maior parte delas na área central da cidade (Figura 2) (EKONOMIO, 2015).

Figura 2 - Localização das empresas de espaços coworking em Curitiba

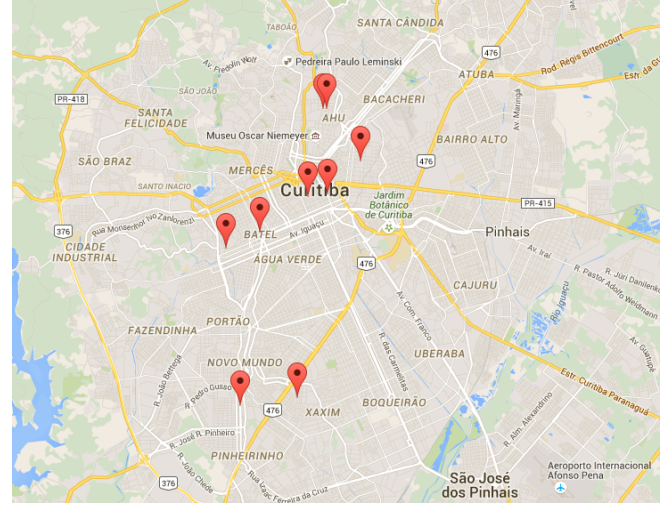

Fonte: Global Coworking Map (2016)

O mapa apresentado na Figura 2 acima, mostra um panorama parcial da distribuição geográfica das empresas de espaço coworking em Curitiba, com a maior parte concentrada na região central e, apenas algumas, na região sul da cidade (GLOBAL COWORKING MAP, 2016). Das empresas presentes nesta cidade é possível classificá-las em duas categorias: franquias ou independentes. Com o crescimento do mercado e, consequentemente, no número de empresas do mesmo ramo, cresce também a necessidade de diferenciação entre elas. Para atingir esse objetivo, o design e a gestão do design podem ser utilizados como ferramentas valiosas (BEST, 2010; KLÖPSH et al., 2011).

\section{A Gestão do Design nos Níveis Estratégico e Tático}

Com o objetivo de aumentar a vantagem competitiva das empresas na economia criativa tanto a gestão do design quanto o design, por suas características diretamente ligadas à solução de problemas centrado nas pessoas, podem oferecer boas soluções à área dos negócios, sociedade e beneficiando a economia como um todo (BEST, 2010).

$\mathrm{Na}$ busca por se tornarem mais inovadoras e competitivas, houve nos últimos 50 anos mudanças significativas nas perspectivas gerenciais dentro das empresas, principalmente após o desgaste do sistema hierárquico taylorista. No decorrer dessas mudanças, está o surgimento da gestão do design, que teve início na relação entre agências de design e seus clientes e evoluiu como uma nova forma de gestão empresarial sendo tanto um processo estratégico quanto uma ferramenta. A gestão do design pode ser considerado uma resposta à necessidade de um modelo organizacional novo, mais flexível, independente e não hierárquico (MARTINS and MERINO, 2008; KLÖPSH et al., 2011).

A partir dessa perspectiva, todas as áreas de gestão dentro das empresas precisam ser reinventadas, criando novas formas de liderar, planejar, avaliar, organizar, contratar e motivar, trazendo o design para dentro da equação (HAMEL, 2011; LOCKWOOD, 2008). A 
velocidade das mudanças ocorridas no mundo no último século, no que tange a tecnologia, economia e mesmo ao processo de globalização, é a mais rápida já enfrentada pela humanidade. A qualidade e expectativa de vida aumentaram exponencialmente, bem como a busca por realização pessoal. Como uma sociedade capitalistas, todas essas transformações tiveram algum impacto nas empresas e corporações, que precisam encontrar meios de se adequar ao futuro (HAMEL, 2011).

Neste contexto, a gestão do design oferece recursos para adequação das empresas às novas necessidades trazidas por essas mudanças, facilitando e melhorando a comunicação dos diferentes grupos e setores dentro das organizações, independente da área de atuação (BEST, 2010). A gestão do design é, portanto, o uso do design para materialização de produtos e processos dentro das empresas. Seu objetivo principal é desenvolver o design como uma competência central, planejando as estratégias corporativas para perfeita integração ao mundo dos negócios (JOZIASSE, 2008; MARTINS e MERINO, 2008). A complexidade desta tarefa parte do entendimento do que é design, seu papel no ambiente corporativo e como pode ser um direcionador para a inovação e o sucesso. A gestão do design não é, portanto, um modelo fixo e linear, como não o são as empresas, operando em diferentes níveis de estratégia de acordo com os objetivos e necessidades de cada empresa, bem como a maturidade do uso do design dentro dela.

Do ponto de vista da maturidade do uso do design nas empresas, esta parte da completa falta do uso do design e vai até, no seu mais alto grau, à incorporação do design como parte da competência central da mesma (DANISH DESIGN CENTRE, 2001). Na sua incorporação, passa pelo nível operacional, restrito ao design tangível e visível em projetos e processos, utilizado como um diferenciador, ou design como estilo; incorpora processos intangíveis, focados principalmente na comunicação interna da empresa, tendo uma função coordenadora e atuando como processo; e no nível estratégico, atua nas características estruturais do ambiente empresarial, planejamento e estratégia, com função transformadora (DANISH DESIGN CENTRE, 2001; MARTINS e MERINO, 2008). O nível estratégico, de acordo com Holston (2011), lida com fatores internos e externos de forma a proporcionar maior competitividade à empresa no mercado no qual ela está inserida (Quadro 1) (MARTINS e MERINO, 2008).

Quadro 1 - Níveis de gestão do design

\begin{tabular}{|l|l|l|l|}
\hline \multicolumn{1}{|c|}{ Influência do Design } & Níveis de decisões & $\begin{array}{c}\text { Níveis de criação de } \\
\text { valor }\end{array}$ & \multicolumn{1}{c|}{ Níveis de competências } \\
\hline $\begin{array}{l}\text { Sobre a oferta: dá um } \\
\text { sentido ao discurso e ao } \\
\text { objeto }\end{array}$ & $\begin{array}{l}\text { Gestão do design } \\
\text { operacional }\end{array}$ & $\begin{array}{l}\text { Atuação sobre a oferta } \\
\text { da organização ou } \\
\text { função diferenciadora } \\
\text { do design }\end{array}$ & $\begin{array}{l}\text { Design ação ou como } \\
\text { competência econômica. } \\
\text { Criação de valor sobre as } \\
\text { funções da organização }\end{array}$ \\
\hline $\begin{array}{l}\text { Sobre os homens: ajuda a } \\
\text { mobilizar e motivar pela } \\
\text { facilidade de circulação de } \\
\text { informações, aproximando } \\
\text { diferentes atores num } \\
\text { mesmo projeto }\end{array}$ & $\begin{array}{l}\text { Gestão do design } \\
\text { tático }\end{array}$ & $\begin{array}{l}\text { Atuação sobre a } \\
\text { empresa ou função } \\
\text { coordenadora do } \\
\text { design }\end{array}$ & $\begin{array}{l}\text { Design funço ou como } \\
\text { competência controladora. } \\
\text { Criação do valor sobre as } \\
\text { funções suporte, em } \\
\text { particular sobre a gestão da } \\
\text { inovação e da tecnologia }\end{array}$ \\
\hline $\begin{array}{l}\text { Sobre a empresa: facilita a } \\
\text { formulação de um projeto } \\
\text { que incite a visão do } \\
\text { núcleo estratégico }\end{array}$ & $\begin{array}{l}\text { Gestão do design } \\
\text { estratégico }\end{array}$ & $\begin{array}{l}\text { Atuação do design } \\
\text { sobre o ambiente } \\
\text { empresarial ou função } \\
\text { transformadora do } \\
\text { design }\end{array}$ & $\begin{array}{l}\text { Design visão ou como } \\
\text { competência psicológica. } \\
\text { Influencia na compreensão } \\
\text { do ambiente e transformação } \\
\text { de procedimentos }\end{array}$ \\
\hline
\end{tabular}


Além dos elementos já mencionados, do ponto de vista corporativo, uma empresa para ser competitiva deve estar à frente de seus concorrentes em algum aspecto, especialmente no que tange à inovação. De acordo com Hamel (2011) há três principais desafios a serem enfrentados pelas empresas com relação à essas alterações. O primeiro está ligado à velocidade das mudanças, que demanda que as empresas sejam ágeis na adaptação a elas. $\mathrm{O}$ segundo é o desenvolvimento da inovação, como trabalho de todos, continuamente e diariamente, devido à competitividade em excesso. E, o terceiro é relacionado à dissipação rápida do conhecimento adquirido, estimulando as empresas a incentivar a paixão e a criatividade internamente (HAMEL, 2011).

\section{Economia Criativa, Coworking e Design}

Inovação é uma competência central do design (ICSID, 2015) e, de acordo com Best (2010) é possível fazer uso do design para aumentar a competitividade comercial das empresas e até mesmo de países inseridos na economia criativa.

\footnotetext{
The term creative economy "refers to the socio-economic potential of activities that trade with creativity, knowledge and information (...) includes thirteen sectors: advertising, architecture, the art and antiques market, crafts, design, designer fashion, film, interactive leisure software (ie. video games), music, the performing arts, publishing, software, and television and radio." (BRITISH COUNCIL, 2016).
}

O desenvolvimento e crescimento da economia criativa, acelerado na década de 80 juntamente com o processo de globalização, destacou o surgimento das chamadas cidades criativas - áreas urbanas concentrando diversidade, conhecimento, tecnologia, inovação e reputação positiva (HOSPERS, 2003). Com cerca de 54\% da população mundial vivendo em áreas urbanas em 2014 e uma expectativa de que esse número suba para 66\% em 2050, as cidades têm o potencial de promover encontros e compartilhar conhecimento tácito, gerando ideias e fomentado a inovação. Administrar adequadamente os espaços urbanos tende a impulsionar desenvolvimento criativo e econômico (JOHNSON, 2011; ONU, 2014).

Administrar esses espaços nas cidades, conforme mencionado, é um desafio face ao crescimento populacional, crises migratórias, processos de gentrificação e possíveis crises econômicas e financeiras (KOTZ, 2009; MERKEL, 2015). Há também o crescimento da demanda por novas formas de trabalho, que também precisa de novos e adequados espaços para se desenvolver (KORUNKA e GERDENITSCH, 2014).

\section{Estudo de Caso}

Considerando-se que a temática trabalhada neste estudo está relacionada a um fenômeno recente, para atender aos objetivos da pesquisa, definiu-se que um estudo de caso contribuiria para uma melhor compreensão do problema e um enriquecimento da discussão quanto aos aspectos abordados na literatura, conforme aponta Gil (2008).

O estudo exploratório teve como objetivo principal identificar as definições feitas pela empresa de espaço coworking no nível estratégico e, posteriormente, comparar e verificar como essas definições se refletiram e materializaram nas ações tomadas pela empresa no nível tático tanto para empregados quanto para clientes. 
A partir da revisão de literatura apresentada, associando gestão do design à economia criativa, e as novas formas de trabalho e espaços coworking, realizou-se a coleta de dados do caso estudado em duas fases. A primeira com dados secundários a partir do site da própria empresa e de três outros websites específicos sobre o assunto coworking: Deskmag, uma revista online sobre o movimento coworking mundial; Coworking Brasil, website com referencias nacionais; e Global Coworking Map, com mapas de localização e estatísticas sobre coworking em âmbito global. A segunda fase, de obtenção de dados primários, foi realizada diretamente junto à empresa estudada por meio de entrevista semiestruturada e observação. A entrevista levantou dados como a missão, visão e valores da empresa, tamanho (por número de funcionários e clientes), competências centrais e serviços oferecidos.

A elaboração do protocolo de coleta de dados para o presente estudo teve início no processo de identificação da necessidade da condução do mesmo. Para isso, foi selecionada uma empresa localizada em Curitiba, fundada em 2010, uma das primeiras a se instalar no país.

Após a realização da entrevista semiestruturada, foi realizada uma visita de observação aos espaços oferecidos pela empresa. A observação simples é uma ferramenta que permite reunir dados sem levantar suspeitas ou gerar modificações no comportamento do grupo ou ambiente estudado. É, também, recomendada para propósitos exploratórios (GIL, 1989). A observação buscou identificar elementos da entrevista aplicados no nível tático da gestão do design da empresa.

\section{Dados Gerais da Empresa}

A empresa selecionada para o estudo completou 6 anos em 2016 (BEUTER, 2016), período em que este estudo exploratório foi conduzido.

No seu início era conduzida apenas pelo fundador-proprietário, que contava com apenas um empregado. Atualmente, possui 6 funcionários, mas o proprietário ainda é a pessoa responsável pela gestão da empresa e do grupo contratado. Cada empregado é responsável pelo gerenciamento de um setor específico da empresa, sendo: comunidade, estrutura, cursos e clientes. Além desses setores, a parte de comunicação conta com 2 pessoas responsáveis. A equipe que compõe o quadro funcional da empresa tem como áreas predominantes de formação jornalismo, comunicação e publicidade, sendo o proprietário também publicitário. A estrutura gerencial é, majoritariamente, plana, sendo cada setor responsável por suas decisões de forma autônoma (BEUTER, 2016).

A missão da empresa é a de catalisar o sonho das pessoas e a visão é a de ser o local onde os profissionais, das mais diversas áreas, encontrem o que precisam para se desenvolver e desenvolver suas ideias, de forma inovadora (BEUTER, 2016). Os valores se materializam em oferecer uma estrutura física adequada, permitindo a criação de redes de contatos, facilitando o aprimoramento da formação profissional e pessoal e divulgando o trabalho dos clientes, por meio do website da empresa e dos eventos por ela promovidos (BEUTER, 2016).

Com o seu crescimento, a empresa, recentemente, mudou-se de um espaço de cerca de $200 \mathrm{~m} 2$ para um novo, no qual está localizada hoje, com mais de $700 \mathrm{~m} 2$. Essa área ocupa dois pavimentos e oferece, atualmente, três escritórios privativos (com possibilidade ampliação nesse número sob demanda); duas grandes áreas com estações de trabalho não fixas; três salas de reunião (uma para 9 pessoas e as outras duas para 14 pessoas cada); e duas áreas que podem, facilmente, transformar-se em auditórios que variam em capacidade, podendo abrigar uma plateia de 20 a 200 pessoas, para cursos, oficinas, palestras etc. Além dos espaços de 


\section{GAMPI}

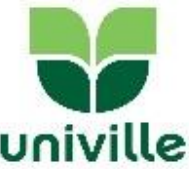

trabalho compartilhados, a empresa oferece ainda uma recepção, café e água, estrutura de cozinha completa, serviço de limpeza dos espaços, estacionamento para bicicletas e guardavolumes (Figura 3) (BEUTER, 2016).

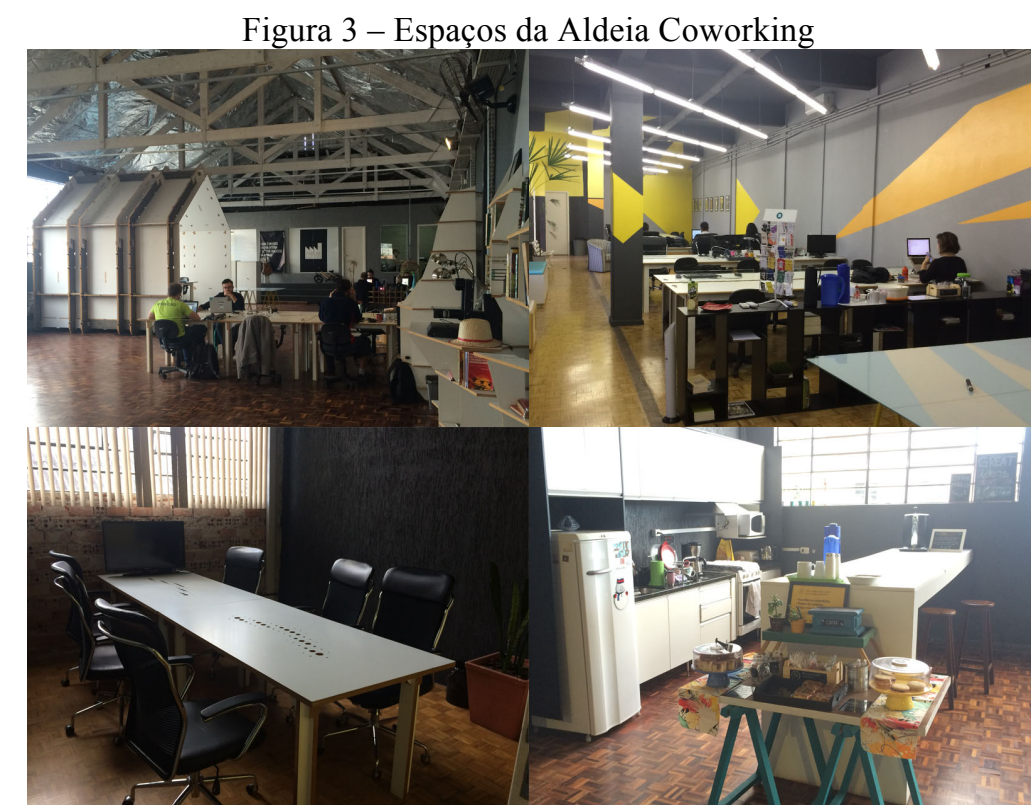

Fonte: Os Autores (2016)

Os espaços, conforme Figura 3, são bastante amplos e ventilados, com design contemporâneo e estilo industrial. Os acabamentos são simples e prezam pela solução mais adequada pelo melhor custo, de forma a manter aberta a possibilidade de modificações futuras conforme demanda.

O design dos espaços, bem como a identidade visual da empresa foram desenvolvidas por empresas contratadas, sendo a primeira desenvolvida por um arquiteto e, a segunda, por uma agência de design (BEUTER, 2016).

Os planos oferecidos pela empresa são divididos por horas ou tempo integral, havendo a possibilidade de aderir a uma assinatura apenas para o uso do endereço comercial e divulgação do nome no site da empresa. Dos atuais 108 assinantes, mais da metade faz uso desta última opção (Quadro 2) (ALDEIA COWORKING, 2016).

Figura 3 - Espaços da Aldeia Coworking

\begin{tabular}{|l|c|c|c|c|c|c|}
\hline Plano & $\begin{array}{c}\text { Rede } \\
\text { (endereço) }\end{array}$ & $20 \mathrm{~h}$ & $50 \mathrm{~h}$ & $100 \mathrm{~h}$ & $150 \mathrm{~h}$ & FULL \\
\hline $\begin{array}{l}\text { Horas disponíveis } \\
\text { mensalmente }\end{array}$ & $\mathrm{X}$ & $20 \mathrm{~h}$ & $50 \mathrm{~h}$ & $100 \mathrm{~h}$ & $150 \mathrm{~h}$ & ilimitado \\
\hline $\begin{array}{l}\text { Horas gratuitas das } \\
\text { salas de reunião }\end{array}$ & $\mathrm{X}$ & $\mathrm{X}$ & $1 \mathrm{~h}$ & $2 \mathrm{~h}$ & $3 \mathrm{~h}$ & $4 \mathrm{~h}$ \\
\hline
\end{tabular}

Fonte: Adaptado de Aldeia Coworking (2016)

Os profissionais que utilizam os serviços da empresa estão, normalmente, ligados à área criativa o conhecimento, sendo predominantemente designers, publicitários, fotógrafos, arquitetos etc. Entretanto, a empresa não possui um grupo de profissionais alvo, sendo 
possível verificar a presença de profissionais das mais diferentes áreas, como advogados, engenheiros, tradutores, professores de idiomas, entre outros(BEUTER, 2016).

$\mathrm{Na}$ observação dois dos escritórios privativos estavam em uso, bem como duas das salas de reunião e diversas estações de trabalho compartilhadas também. Os escritórios privativos são exclusivos para alguns assinantes do plano FULL que, geralmente, são pequenas empresas ou empreendedores que se beneficiam dos baixos custos, boa rede de contatos e visibilidade oferecidos pela empresa de espaço coworking.

\section{Discussão}

Para a validação do presente estudo, foi utilizada a estratégia de triangulação de dados, relacionando todas as informações obtidas por meio da revisão de literatura e da coleta de dados primários e secundários. Essa estratégia permitiu traçar as relações entre os níveis tático e estratégico da gestão do design adotados pela empresa de coworking em estudo.

A partir os dados coletados com o estudo de caso exploratório e sua relação com a revisão de literatura, é possível sugerir que a gestão do design estratégico, quando usada como uma ferramenta de diferenciação pode promover a inovação e um ambiente de negócios mais saudável (BEST, 2010; KLÖPSH et al., 2011), como se observa no fato de, ao longo da entrevista, a concorrência com as demais empresas do ramo não ser enxergada como ameaça mas como havendo espaço para todos.

Do ponto de vista do caso estudado, percebe-se também que a empresa utilizou conceitos de gestão do design como guia de negócios, mesmo que o termo não tenha sido mencionado na entrevista ou demais materiais.

Do ponto de vista do nível estratégico da gestão do design, a empresa tem bem definidos sua missão, visão e valores. Esses elementos se transmitem na estrutura organizacional mais plana, no senso de comunidade promovido pelas empresas e também pelo Manifesto da empresa, que fica à mostra em um quadro ao lado da recepção, favorecendo a estrutura de fluxo proposta por KLÖPSH et al. (2011) e em consonância com as bases do coworking apresentadas por Moriset (2014).

Por se tratar da primeira empresa dessa categoria na cidade, ela está posicionada à frente em relação aos concorrentes que chegaram depois. De acordo com Hamel (2011), Johnson (2011) e Klöpsh et al. (2011) a liderança é, por si só, um ponto favorável do ponto de vista da inovação, podendo e devendo criar um ciclo de novas ideias por meio de processos internos e externos de forma a manter essa liderança ao longo do tempo.

Entretanto, todas essas estratégias seriam apenas informações e planos se não fossem colocadas em prática (KLÖPSH et al., 2011). O uso do design como coordenador no processo de criação de valor e de inovação tende a favorecer a empresa (MARTINS E MERINO, 2008). Partindo de Martins e Merino (2008), Best (2010) e Klöpsh et al. (2011) é possível reconhecer entre as ações tomadas pela empresa as relacionadas ao nível tático da gestão do design, devido a às características organizacionais materializadas na empresa por meio da gestão participativa e dos clientes e coworkers terem voz ativa na configuração dos espaços físicos.

Apesar do espaço físico consideravelmente grande, cerca de $700 \mathrm{~m} 2$, do ponto de vista de recursos humanos a empresa pode ser considerada pequena, o que facilita os processos de comunicação e integração entre seus diferentes setores. Holston (2011) reforça ainda que as ações tomadas se refletem positivamente para os clientes e para a própria organização. 
As abordagens mais horizontais, como se configura o espaço físico da empresa e as relações interpessoais estabelecidas pela hierarquia apresentada, tendem também a proporcionar a criação e manutenção de cultura criativa, na qual a colaboração pode ser vista como reflexo da estratégia adotada, gerando maior confiança e tornando a empresa mais competitiva, com reações mais rápidas às mudanças do mercado (HOLSTON, 2011).

O desenvolvimento da economia criativa, fator influenciador externo, também tem papel importante na evolução da área na qual a empresa está inserida. O contexto de crescimento do modelo de negócio de corporações de espaço coworking, conforme Merkel (2015), está diretamente ligado à globalização, urbanização e ao potencial socioeconômico de atividades criativas, cujas profissões relacionadas estão entre as principais atuantes nos espaços existentes (FOERTSCH, 2015). É nesse cenário que a empresa estudada como caso surgiu e tem crescido desde 2010. Um bom parâmetro dessa expansão pode ser verificado pelo aumento do espaço físico de $200 \mathrm{~m} 2$ até 2015 para $700 \mathrm{~m} 2$, e em relação aos recursos humanos, que teve início com um único colaborador e conta atualmente com 6 , bem como a ligação direta da formação dos mesmos com a área criativa, podendo ser, este, um indicador da influência do cenário externo dentro da empresa.

De acordo com Ekonomio (2015) cerca de $1 / 3$ de todos as empresas de espaço coworking atuantes no Brasil em 2015 mencionaram não direcionar a atração e manutenção de clientes a nenhuma área profissional específica. Ainda segundo o mesmo autor, apesar do não direcionamento, a maior parte dos usuários dos espaços identifica-se como pertencendo, majoritariamente, às seguintes áreas: negócios sociais, design, fashion, educação, advogados, tecnologia e artes. Em relação à pesquisa realizada por Ekonomio (2015), o caso estudado em Curitiba possui comportamento em relação ao direcionamento conforme estudo, bem como o público atendido é similar.

A maioria das áreas mencionadas pelos usuários de espaços coworking no Brasil (EKONOMIO, 2015), assim como na empresa estudada, faz parte do grupo considerado como pertencendo setor de economia criativa, conforme o British Council (2016). Esses elementos reforçam a teoria de que o local pode tem potencial para promoção de encontros criativos e inovadores, de acordo com Johnson (2011).

\section{Considerações Finais}

É possível verificar que há elementos claros do nível estratégico da gestão do design definidos pela empresa de espaço coworking estudada, apesar do termo, em si, não ter sido mencionado ao longo do estudo. A clara definição da missão, visão e valores da empresa como direcionadores de suas ações interna e externamente são fortes indicadores desta presença. Do ponto de vista de como essas definições se refletem no nível tático, a forma de atuação da empresa, que inclui sistema organizacional mais plano e participativo, demonstra a aplicação dos itens definidos no plano de ação proporcionando a criação e manutenção de cultura criativa. É possível perceber neste estudo que a gestão do design está presente e ativa na organização.

Entretanto, por limitação do próprio estudo exploratório, não foi possível identificar como essa linha de gestão chegou até a estrutura organizacional.

Nesse cenário, recomenda-se que pesquisas futuras investiguem de forma mais aprofundada como empresas, particularmente as atuantes no setor da economia criativa e com proximidade à área do design, aplicam os conceitos de gestão do design, mesmo que de forma empírica. A partir dessa investigação, buscar identificar os caminhos percorridos pelos 
gestores para essa aplicação, como outras linhas de pensamento e estudos gerenciais e organizacionais, e como seria possível tornar o conhecimento da gestão do design mais próximo destes gestores.

\section{Referências}

ALDEIA COWORKING. Planos para coworkers. Impresso gráfico. 2016.

BEST, K. The Fundamentals of Design Management. AVA Publishing SA. 2010.

BEUTER, J. Entrevista concedida pela Gerente de Comunidade da Aldeia Coworking [maio, 2010]. Entrevistador: Gheysa C. Prado. Curitiba, 2016. 1 arquivo .m4a (17 minutos).

BILANDZIC, M, FOTH, M. Libraries as coworking spaces. Library Hi Tech, v. 31, n. 2, p. 254-273, 2013.

\section{BRITISH COUNCIL. What are Creative Industries and Creative Economy.}

DANISH DESIGN CENTRE. The Design Ladder: Four steps of design use. 2001.

JOHNS, T. and GRATTON, L. The Third Wave of Virtual Work. In: Harvard Business Review. January-February, 2013.

DE PELLEGRIN, L. and FOERTSCH, C. 1ST GLOBAL COWORKING SURVEY Disponível em: <http://bit.ly/1TWzOTJ>. Acesso em: 13/04/2016. 2011.

EKONOMIO. Censo 2015: Uma breve análise sobre o mercado de Coworking brasileiro.

FOERTSCH, C. 2010 Disponível em: <http://bit.ly/1Ug0hHJ>

FOERTSCH, C. 2011. Coworking Study: The Coworker in Deskmag. Published 14/10/2010. Disponível em: $<$ http://bit.ly/1Ug0hHJ $>$. Acesso em: 14/04/2016.

FOERTSCH, C. 2015. First Results Of The New Global Coworking Survey in Deskmag. Public.: 20/11/2015. Disponível em: <http://bit.ly/1O3NT1j>. Acesso em: 14/04/2016

GANDINI, A. The rise of coworking spaces: A literature review. Ephemera: theory and politics in urban organizations. 2015 V. 15 (1), p.193-205, 2015

Gentrification [Def.1]. (n.d.). In Merriam Webster Online. Busca em: 15/04/2016

GIL, A. C. Métodos e técnicas de pesquisa social. São Paulo: Atlas, 2008.

HAMEL, G. Reinventing the technology of human accomplishment. In: Management Innovation eXchange (MIX). 2011 
HILL, J., et. al. Defining and conceptualizing workplace flexibility. Community, Work \& Family, 2, 149-163, 2008

HOLSTON, D. The strategic designer: tools and techniques for managing the design process. Cincinnati: How books, 2011.

ICSID. 2015. Definition of Industrial Design. Acesso em: 27/04/2016.

JOHNSON, S. Where Good Ideas Come From: the natural history of innovation. Riverhead Books, 2011

JOZIASSE, F. Corporate Strategy: Bringing Design Management into the Fold. In: Lockwood, T. and Walton, T. (ed.) Building Design Strategy: Using Design to Achieve Key Business Objectives. New York: Allworth Press, 23-32, 2008

KLÖPSH, C.; COSTA, F. X.; MOZOTTA, B. B. de.. Gestão do Design: Usando o design para construir valor de marca e inovação corporativa. Tr. Lene Belon Ribieiro. Porto Alegre: Bookman, 2011

KORUNKA, C. and GERDENITSCH, C. New Ways of Working and Quality of Working Life: A Macroergonomic Approach in Human Factors in Organizational Design and Management Nordic Ergonomics Society Annual Conference, pp. 267-272. 2014

KOVÁCS, I. Novas formas de organização do trabalho e autonomia no trabalho. Sociologia, problemas e práticas, 52:41-65, 2006

LEFORESTIER, A. The Co-working space concept: CINE Term Project. Indian Institute of Management. 2009.

LOCKWOOD, T. In: LOCKWOOD, T.; WALTON, T. (ed.). Building design strategy: using design to achieve key business objectives. pp. 3-41. New York: Allworth Press, 2008.

MARTINS, R. F. de F.; MERINO, E. A. D. 2008. A Gestão de Design como Estratégia Organizacional. 1 ed. Londrina: EDUEL. 250p.

MERKEL, J. Coworking in the City. Ephemera: theory \& politics in organization. v.15 (1) p.121-139, 2015. Disponível em: <http://bit.ly/1PhWJc4>. Acesso em: 20/08/2015

MORISET, B. 2014. Building new places of the creative economy: the rise of coworking spaces. In: Geography of Innovation International Conference, 2, Utrecht, 2014.

ONU. World's population increasingly urban with more than half living in urban areas. Nova Iorque, 2014. Disponível em: <http://bit.ly/1PhX5PS >. Acesso em: 05/08/2015.

YIN, R. K. Estudo de Caso: Planejamento e Métodos. 4ª .Ed. Porto Alegre: Bookman, 2010. 